\title{
CHILE: ¿TRANSICIÓN O DEMOCRACIA LIMITADA?
}

\author{
Boris Falaha L.
}

\section{PRESENTACIÓN}

Este trabajo constituye la continuación de una primera exposición realizada en el Congreso Internacional de Sociología en lengua francesa (Lyon, 4-10 de julio de 1992) y en una Mesa Redonda sobre los resultados electorales de las elecciones municipales en Chile y la transición, que se efectuó en la Maison de L'Amerique Latine el 28 de julio de 1992.

Agradezco, de manera muy especial, a los restantes panelistas e interlocutores de dicho debate y, en particular. a Werner Ackermann (C.N.R.S. - CESO, París) con quien discutimos detenidamente este artículo que fue enriquecido con sus observaciones.

Esta colaboración nos compromete a ambos a trabajar, en forma conjunta, en el análisis de los procesos de construcción de la democracia en Chile.

Intentamos, en el presente trabajo, caracterizar la situación política chilena. Ellos nos induce a definirla como una democracia limitada. dominada por una ideología unicitaria. consensual y homogénea de la sociedad.

Analizamos las condiciones políticas e ideológicas para alcanzar la democracia plena en Chile.

Presentamos, para concluir, un análisis del debate entre democracia como resultado de la hegemonía social (Karl Schmitt) y democracia como procedimiento y espacio de regulación de diferencias (Kelsen y otros).

\section{INTRODUCCIÓN}

En Chile, la pérdida de la democracia tuvo trágicas consecuencias: muertes, torturas, represión, dictadura. Los vencidos fueron marginados o exiliados. La legitimidad democrática del gobiemo como la de los opositores, la legitimidad política de la derecha como la de la izquierda, la de los empresarios como la de los trabajadores fue destruida por la fuerza, principal elemento Jel régimen autoritario que reinó durante 18 años.

La legitimidad democrática no puede, por lo tanto, ser restablecida automáticamente - las democracias se destruyen por medio de la violencia pero no sucede así con las dictaduras. Cabe preguntarse. entonces, sobre el estado actual de la vida política chilena.

¿Se trata de un período de transición hacia una democracia verdadera o de una democracia imitada, sin porvenir. que acomoda y resguarda los valores del régimen autoritario precedenta?.

Nos esforzaremos en delimitar las características de esta situación para entender el proceso los rasgos de una eventual evolución. 


\section{RIGIDEZ JURÍDICA}

Es necesario. en primer lugar, hacer una breve reseña sobre la situación jurídica y electoral en Chile.

El marco jurídico de la Constitución de 1980, vigente en la actualidad, y sus disposiciones no democráticas no están limitadas en el tiempo: el senado incluye senadores designados por el gobierno (militar), consagra la supremacía del poder militar y de sus tribunales, coarta la renovación del poder judicial.

Esta rigidez se halla consolidada por el sistema de quórum constitucional que exige mucho más que la mayoría absoluta para aprobar las modificaciones constitucionales.

La ley electoral restringida no hace más que acentuar dicha rigidez, pues para aprobar modificaciones institucionales se requiere dos tercios de los votos (Art. 116 de la Constitución). En los términos fijados por esta ley, cada circunscripción genera dos elegidos a la Cámara: el primero es aquél que obtiene la mayoría absoluta de los sufragios, el segundo necesita sólo el $33 \%$ de los votos para resultar electo.

Este sistema, llamado binomial, permite a la derecha tener el 50\% de los diputados con apenas el $33 \%$ de los votos. Por lo tanto, no tienen ningún interés en cambiarlo, por el momento.

\section{RESULTADOS ELECTORALES Y RIGIDEZ POLÍTICA}

Examinemos ahora la evolución de los resultados electorales: no se produjo un cambio notorio entre el plebiscito (octubre 1989) y la elección presidencial efectuada 14 meses más tarde, a pesar del restablecimiento de la práctica democrática durante ese período. Sólo podemos hablar de un aumento del uno por ciento en la votación de la coalición democrática.

Los resultados de las últimas elecciones municipales (junio 92) han confirmado lo expresado precedentemente, en lo que concierne al total de votos obtenidos por cada uno de los dos grandes bloques (partidos democráticos — concertación, partido comunista y socialista disidentes- y sector autoritario). Sin embargo, se observa una evolución significativa al interior de cada uno de ellos.

En el seno del bloque pro Pinochet, Renovación Nacional y Unión Demócrata Independiente. han consolidado sus posiciones $-18 \%$ de los votos para los primeros, $12 \%$ para los segundos; en tanto que los partidos populistas de derecha (Unión de Centro Centro) van en declinación y no recogen más que un $8 \%$ de los votos. Tal como se advierte. la suma sobrepasa el $33 \%$ de los votos necesarios para obtener la mitad de los asientos en el Parlamento (sin contar a los senadores designados) en caso de elecciones legislativas.

En el seno del bloque democrático (Partidos de la Concertación) la Democracia Cristiana y sus aliados directos obtienen 35.6\% de los votos. Cabe destacar que el Partido Radical, que está incluido, ha elevado su porcentaje de $1.5 \%$ a $5 \%$, un indicador importante del retorno de los parlidos tradicionales. Los nuevos minipartidos (verdes, ccologistas, humanistas) no superan. en conjunto el $2 \%$.

En el otro componente de la concertación, el Partido Socialista y el Partido por la Democracia obtienen, respectivamente, $8.5 \%$ y $9.2 \%$ de los sufragios. Este componente obtiene, pues. en total $17.6 \%$ de los votos. 
CHLE: ¿TRANSICIÓN O DEMOCRACIA LIMITADA'?

Respecto al Partido Comunista y a los socialistas disidentes -pero pertenecientes a lo que llamaríamos el bloque democrático-alcanzan en conjunto, contrariamente a las previsiones pesimistas, un significativo $6.6 \%$.

Sin embargo, si sumamos estos resultados a los anteriores, el total de los partidos. -llamados de izquierda, no demócrata cristianos-suman un $24.2 \%$, inferior al tercio de los votos.

Entre 1989 y 1992, tales resultados muestran un levísimo aumento de los sufragios en favor de la democracia (alrededor del uno por ciento) y una mantención importante de los partidos tradicionales. Ello revela igualmente la posición de debilidad de los partidos de izquierda respecto a la Democracia Cristiana, pues por sí mismos no pueden asegurarse una representación parlamentaria. Lo anterior los obliga a permanecer en el seno de la coalición gubernamental y a intentar influirla desde el interior.

Esto debilita considerablemente su aspiración a presentar su propio candidato a las próximas elecciones presidenciales, aunque sólo fuera para una primera vuelta, ya que cllas se realizan simultáneamente a las elecciones parlamentarias. Parece difícil que a un mismo acto electoral se presenten coaliciones diferentes, una para la elección presidencial y otra para la parlamentaria. $^{1}$

En todo caso, basándose en dichos resultados electorales, en la situación actual los antipinochetistas o coalición democrática, no lograrían el $66 \%$ de los sufragios requeridos para obtener en el parlamento una mayoría suficiente que permitan modificar la Constitución.

Los pro pinochetistas poseen. en consecuencia, todos los instrumentos legales necesarios para bloquear el proceso de transición hacia la democracia. El único medio para derribar esta barrera es competir en el terreno político, a fin de ampliar la plataforma electoral y conformar una base electoral más sólida. Se torna indispensable. por lo tanto, reactivar el debate político y superar la modalidad consensual sobre la cual se funda su práctica en la actualidad.

\section{CONSENSO Y CAMBIOS}

En efecto, el consenso que reina en el presente es heredado de la negociación en torno a la constitución de 1980 y. de hecho, mantiene los valores establecidos en la época anterior. Los partidos políticos vigentes se reorganizaron durante el último período de la dictadura, sobre todo luego de la movilización social de los años 83-86. a partir de la cual obtuvieron, en parte. su legitimidad. ${ }^{2}$

La fuerte atomización social provocada por al dictadura se reflejó en los partidos de la izquicrda tradicional, que se dividieron en múltiples fracciones.

Al comienzo de este proceso de reorganización de los partidos políticos, su legitimidad se basa en lazos personales y de confianza. fundados en la reciprocidad. Reconocer al otro significaba ser reconocido uno mismo. La suma de las legitimidades reconocidas de cada uno constituía la legitimida del sistema. Se instaló un proceso de cooptación que originó cierto sitismo y, en alguna niedida, un grado de separación entre los dirigentes, sus bases políticas y la población.

\footnotetext{
1 El lanzamiento de la candidatura del ex Ministro Latgos, ha pueste en relieve este tema de discusion.

z Véase Rodrigo Baño. De Alugushas a Pamcos. Santago de Chile, Amerinda, 1992.
} 
Posteriormente. los partidos políticos buscaron establecer su propia legitimidad, independiente del mutuo conocimiento, a través de la realización de elecciones internas, tanto en el Partido Demócrata Cristiano como en los otros. El Partido Socialista, por ejemplo, escogió. por primera vez desde sus inicios hace 60 años, a los miembros de su Comité Central mediante elecciones directas.

No obstante, la práctica interna de cada partido continuó siendo elitista y centralizadora y las relaciones entre las distintas fracciones políticas prosiguieron obedeciendo siempre al modelo consensual inicial. El citado modelo evita todo lo que pueda separar y ser motivo de diferencia. El contenido de los debates políticos - su propio objeto- descarta rigurosamente toda referencia histórica y limita su horizonte temporal al presente o al futuro inmediato. ${ }^{3}$

Ello involucra un pragmatismo erradamente llamado no ideológico de los partidos, que no diferencia los medios de las finalidades. En efecto, este pragmatismo no sólo constituye una estrategia política.

Es una concepción de la sociedad que sitúa entreparéntesis los conflictos y las exclusiones. En la práctica, es una visión ideológica del mismo tipo que el nacionalismo, el corporativismo, el populismo, etc. En tal sistema, el actor político protagónico es el gobierno y no los partidos políticos.

El propio gobierno negocia políticamente los proyectos de ley antes de presentarlos en el Parlamento. El acuerdo político precede al debate legislativo, reduciendo éste a una simple ratificación. La influencia del poder militar - Consejo de Seguridad Nacional, Consejo de Generales, Pinochet en la Comandancia en Jefe de las Fuerzas Armadas- puede explicar esta prudencia del gobierno civil, que reafirma el modelo consensual.

Una de las consecuencias de dicho modelo, al nivel de los actores políticos. es que sus campos de actividad devienen a-históricos, sin referencia al pasado ni al futuro. Las diferencias se enmarcan en un espacio limitado, donde son más fáciles de negociar. Los actores políticos procuran mantener este espacio restringido, autolimitándose. Dicha consensualidad, que puede justificarse en determinados momentos, supone una sociedad homogénea y no contradictoria. Sobre este plano pueden desarrollarse ideologías hegemónicas y autoritarias, que niegan las diferencias e impiden los debates que permitan su actualización y regularización. Ahora bien. tal regulación de las diferencias es la tarea propia de la democracia.

El modelo consensual representa una primera apertura en la visión autoritaria del orden social. Supera la obediencia mediante el acuerdo unánime. pero no admite el debate sobre las diferencias. La democracia, por el contrario, se caracteriza por la aceptación de las diferencias y la aplicación de procedimientos para alcanzar acuerdos negociados.

Para escapar a este consenso a-político y a-histórico, para avanzar hacia una democracia verdadera, se requerirá tolerar un debate más abierto al dominio político, en el plano cultural. en la concepción misma de la democracia.

\footnotetext{
${ }^{3}$ Sin embargo, conviene destacar que los acuerdos entre la D.C. y el P.S. no son únicamente puntuales: hay unat real convergencia sobre la justicia social y las políticas de redistribución. Cf. F. Boeninger. E. Comea, A. Flistisch. A. Foxley y C. Ominami.
} 


\section{DE LA CRÍTICA A LA POLÍTICA}

En el dominio político se hace necesario reformular la concertación. Se puede obtener una mejor cohesión fijando prioridades que permitan desbloquear la situación (modificar la ley electoral, por ejemplo) y la apertura de verdaderos debates políticos.

La ampliación de la base electoral involucra el abandono del lenguaje consensual y la adopción de un lenguaje político; la superación de esta ideología del no conflicto, de la unicidad y de la cohesión social, de esta visión de una sociedad sin confrontaciones, que conduzca a la visión de una democracia capaz de dejar expresarse diferencias y diferendos, minoría y mayoría, para utilizarlas en un proceso de acuerdos negociados y de concesiones recíprocas. Sin embargo, tal debate sólo es posible, si se acepta hacer una profunda crítica cultural. cuestionar la legitimidad basada en las armas, revalorizando los principios democráticos del Derecho sobre la fuerza.

Es necesario que se instituya una reflexión política y crítica sobre la ciudadanía, los derechos del hombre, la responsabilidad cívica y social de los electores así como de los elegidos y que se emprenda una discusión profunda sobre los abusos de la dictadura. Una democracia real no puede nacer sin estas aclaraciones preliminares. Ningún país, ninguna sociedad lograr desarrollarse en el olvido de su propia historia. ${ }^{4}$

A diferencia de Uruguay, Chile no ha tenido un movimiento de reflexión crítica sobre la violación de los derechos humanos. Aunque Uruguay votó en seguida un referendum para una Ley de Punto Final, la discusión anterior a su promulgación representó una verdadera catarsis social. En efecto, no se trata de venganza sino del conocimiento de nuestra propia historia, conocimiento indispensable para que una democracia pueda eliminar todo riesgo de sufrir de nuevo la violación del derecho por la fuerza.

Sin este conocimiento y esta conciencia del pasado, los actores políticos viven en la rigidez $\because$ en el bloqueo propios de una situación de alineación social. Ahora bien, la sociedad chilena le hoy presenta todavía los síntomas de esta alineación.

La psiquiatría social ha analizado el síndrome de Estocolmo: manifestación de simpatía. Je apoyo, de los rehenes a sus carceleros. Dicho fenómeno, estudiado por los doctores Georges Gachnochi y Norbert Skernik (clínicos en Etampes y la Maison Blanche) ${ }^{5}$ nos ha inducido a ?ensar en la conducta de ciertos políticos y dirigentes sindicales, víctimas de la dictadura. quienes, el día de la transmisión del poder al nuevo Presidente Aylwin. se atropellaban para ser totografiados al lado de Pinochet. A éste lo podríamos denominar síndrome de Valparaíso, una - ecuela entre tantas otras dejada por la praxis cotidiana de una socieđad autoritaria. La atracción z jercida por la dictadura sólo puede ser superada por un trabajo crítico y colectivo.

Pero, le hemos dicho: igualmente, es necesario llevar el debate sobre la noción misma de temocracia.

\footnotetext{
'El Informe Rettig. constituye un imponante apone para establecer la convicción de las nuertes ocurridas durante dictadura, pero no se transformó en el centro del debate.

" "Los efectos paradojales de la toma de rehenes», en Revic Internationale de Science Sociales, No 132, mayo 1992.
} 


\section{LA DEMOCRACIA COMO INSTRUMENTO DE MODERNIZACIÓN}

En Chile, como en todos los países occidentales, se ha opuesto, durante largo tiempo. la noción de democracia popular a la de una democracia burguesa. Esta oposición implicaba una visión ideológica de la democracia.

El concepto de democracia burguesa suponía la hegemonía social de la burguesía, mientras que el de democracia popular suponía la hegemonía social de la clase obrera. Por lotanto, ambos implicaban la hegemonía de una clase sobre el resto de la sociedad. Proponían una definición ideológica de la democracia, que consideraba la supresión de las diferencias culturales y sociales y la creación de un espacio cultural y social homogéneo.

En otros términos, la democracia no podía funcionar más que en un mundo social homogéneo o con vocación de hegemonía; vale decir, con una ideología unicitaria.

La discusión opone, actualmente, a esta visión ideológica un concepto de democracia en tanto que espacio de discusión y procedimiento de debates, permitiendo la confrontación de opiniones y valores diferentes y su regulación.

En Chile, la diferencia entre estas dos concepciones de la democracia no se percibe con claridad ni se debate actualmente.

Citemos aquí, como ejemplo, varios artículos aparecidos en la prensa chilena sobre el tema de las manifestaciones raciales de mayo de 1992 en los Estados Unidos. Todos ellos destacaban la ventaja que representaba para la sociedad chilena su homogeneidad racial y cultural, condición que le evitaría tales explosiones. En este sentido, los autores estigmatizaban las reivindicaciones culturales de los indigenas en Chile.

En consecuencia, las diferencias económicas, culturales, étnicas y sociales se borran, en beneficio de una pseudo homogeneidad nacional.

Lo anterior, refleja acertadamente la ideología autoritaria dominante, que se funda en una visión unicista de la sociedad, donde la coherencia que hace reinar una jerarquía prima sobre el reconocimiento de los actores sociales diferentes.

Esta concepción dominante sobrevalora la idea de democracia basada en la homogeneidad sociocultural y llama a la identidad nacional.

Por lo tanto, conviene clarificar dichos conceptos, a fin de introducir un verdadero debate político alrededor de la democracia.

En el análisis del concepto de democracia debemos recordar que éste ha sido asociado, en la época moderna, al liberalismo político, por una parte y al igualitarismo social, por otra. En su relación con el liberalismo político, reencontramos toda la tradición inglesa que vincula la democracia, por un lado, con el parlamentarismo y por otro, con el desarrollo económico e industrial. En tal perspectiva, el desarrollo económico no implica un igualitarismo sino la libertad de emprender. Ahora bien, a comienzos del siglo. Karl Schmitt considera que el régimen democrático no puede analizarse sólo en esos términos sino que exige esencialmente un marco de homogeneidad sociocultural. Los representantes y los representados, en un régimen democrático, deben tener un lazo común directo para asegurar esta representación, que sobrepasa la relación entre electores y elegidos. Esta visión supone una homogeneidad social basada en la relación entre representante y representado y, por lo tanto, reduce el rol de los partidos políticos en tanto que instancias intermedias de representación y de organización de los electores. Ella proporciona, así, las bases teóricas a los regímenes autoritarios facistas. 
Pero en la misma época ya sc encuentra el análisis de autores como Kelsen. que funda la Jemocracia sobre el principio de la libertad: un sistema donde se procura conciliar las libertades individuales, en el cual cada tema puede armonizarse con los otros para realizar el bien común. preservando los intereses individuales y privados. En la vision de Kelsen. la democracia es un proceso que se fundamenta en la aceptación de un relativismo político y posibilita un debate uue no está nunca acabado. El equilibrio, para Kelsen. es el resultado del proceso democrático $\because$ no el producto de una homogeneidad social previa.

En la actualidad. autores tales como Claude Lefort y Chantal Mouffe desarrollan también ia noción de una democracia basada en el pluralismo y que descarta la idea de un estado totalizador o de una visión única del bien comín.

Al mismo tiempo, se podrían retomar hoy las críticas que hacía Bakunín, en su propia epoca, a Marx (el rol del Estado en el proceso de elaboración socialista).

El reestablecimiento de una verdadera democracia en Chile no puede evitar un debate sobre la naturaleza y las características de los modelos democráticos posibles. En efecto, estos modelos son los únicos capaces de reducir las grandes exclusiones económicas, sociales. culturales y políticas en las cuales vive aún hoy una parte importante de la sociedad chilena.

\section{CONCLUSIONES}

Para concluir, resumiendo podríamos hacer las siguientes observaciones:

- La situación chilena actual, más que de transición hacia una democracia, que supone pasos previstos de A a B, a causa de su rigidez, se halla limitada. Así, en vez de hablar de una transición hacia la democracia tenemos que hablar de una democracia limitada.

- El paso de una democracia limitada a una democracia real no puede concretarse sin una negociación política. una crítica cultural de la enajenación dominante y una reflexión en torno a los alcances y características de la democracia.

Lo anterior. demanda superar la alincación como también la permanencia de la ideología autoritaria. gracias a la revalorización de la organización sobre el orden. de la asociación sobre la disciplina.

Reemplazar las ideologías unitarias y hegemónicas por la política que reconoce las diferencias.

Reemplazar los partidos pragmáticos por partidos políticos que regulen esas diferencias. Ello, tal vez. permita renovar los procedimientos consensuales por el procedimiento político y ampliar las bases necesarias para obtener una mayoría electoral que apoye los cambios institucionales. que en la actual situación requicren dos tercios de los votos para ser aprobados.

La acertada gestión económica del gobiemo actual, la inserción lograda por él en los inercados internacionales de capitales, el reconocimiento político que le otorgan las democracias modemas y la confianza ganada a nivel nacional por este gobiemo civil y de derecho permiten creer que la reintroducción del debate político. indispensable para el desbloqueo de la situación. está. desde ahora en el plano de lo posible. 


\section{BIBLIOGRAFÍA}

T. A. Adorno, K. Popper, J. Habermas, De Vienne a Frankort, Ed. Complexes, Paris, 1979.

R. Bax̃o, De Augustos a Patricius, Ed. Amerinda, Santiago, Chile, 1992.

M. Bakunine, La Liberté Chaix de textes. F. Muñoz Ed. J. J. Paunert, Paris 1972.

B. FaLAHA, «Ruoture avec la dictature ou reformulation de la démocratie au Chili», Table Ronde, XIV Congrès de l'Association Internationale de Sociologie de langue française. AISLF Lyon, France, juillet 1992.

G. GaChochig y N. SKuRNIK, «Penser la violence», en Revue Internationale des sciences sociales, № 132 mai 1992 , Paris.

M. A. GARRETón, «Transición ni mucho ni poco». Documento de Trabajo, FLACSO, 1992.

J. HaBERmas, Le discours philosophique de la modernité, Ed. Gallimard, Paris, 1988.

H. KELSEN, "What is Justice?, Justice, law and politics in the mirror of Science», Berkeley, Mit Press 1957.

H. Kelsen, La démocratie, sa nature, sa valeur. Trad. Ed. Económica, Paris, 1988.

N. LeChNER, «L'enjeu de l'Etat Democratique» 1992.

C. Lefort, Essai sur la politique, Paris, Seuil, 1986.

CH. Mouffe, «Penser la démocratie modeme, avec, entre autre, Carl Smith», in Revue Française de Science Politique, Maspéro 1992, Paris.

A. SCHEDLER, "Condiciones y racionalidades de la concertación social. Una revisión del debate latinoamericano». Documento de Trabajo № 23, FLACSO, 1992. 